\title{
Geotecnologias aplicadas: relato de disciplina eletiva desenvolvida na educação básica
}

\author{
André Luiz da Conceição
}

https://doi.org/10.4322/mp.978-65-991393-8-3.c5

\begin{abstract}
Resumo
Atualmente o Brasil passa por um período de transição curricular na educação básica, fato que impõe desafios e oportunidades às disciplinas escolares e instituições de ensino. A possibilidade de escolha, por parte dos estudantes do ensino médio, e de seus itinerários formativos deu margem para o surgimento de disciplinas eletivas. Nesse sentido, o objetivo desse artigo é relatar o desenvolvimento da disciplina eletiva de Geotecnologias Aplicadas durante o segundo semestre de 2019, em três colégios particulares, sendo dois localizados em São Paulo-SP e outro em Jundiaí-SP. A disciplina foi ofertada na estrutura metodológica de uma sequência didática de aprendizagem com oito encontros presenciais quinzenais, o que representou 16 aulas de 50 minutos cada. Os resultados obtidos foram agrupados em três categorias de análise, correspondentes às produções cartográficas criadas pelos educandos, mediante a utilização de softwares de geoprocessamento; às exposições orais de projetos que analisaram as transformações espaciais e temporais de regiões do espaço urbano dos municípios de localização dos colégios; e à autoavaliação respondida pelos alunos, alcançando valor de $86 \%$ de menções satisfatórias em relação aos conteúdos aprendidos na disciplina, complementada com relatos descritivos dos discentes destacando aspectos como a possibilidade de maior aprendizado em relação às tecnologias geoespaciais para a realização de estudos socioeconômicos e ambientais. De maneira geral, é possível concluir que a realização dessa disciplina eletiva trouxe resultados positivos no âmbito da educação geográfica, representando um exemplo adequado de prática de ensino diferenciado, contextualizado, crítico e significativo para os estudantes do ensino médio.
\end{abstract}

Palavras-chave: educação básica, ensino de geografia, geoprocessamento, geotecnologias aplicadas, linguagem cartográfica, resolução de problemas urbanos.

\section{Introdução}

A reformulação do currículo da Educação Básica brasileira promovida pela Base Nacional Comum Curricular - BNCC, associada aos principais desafios que envolvem o ensino de geotecnologias no Brasil, representam os dois pilares teóricos desse trabalho, auxiliando inclusive, na compreensão dos motivos que levaram ao oferecimento de uma disciplina eletiva para estudantes do ensino médio.

Em discussão mais intensa desde 2015, por meio da criação da Comissão de Especialistas para a Elaboração da Proposta, a BNCC passou por um período de publicação de versões e discussões junto ao público de interesse, culminando na homologação em 2017, da versão voltada para as etapas da educação infantil e 
ensino fundamental, mediante a Portaria no. 1.570, de 20 de dezembro [1, 2]. Em 2018, foi apresentada à sociedade a versão da BNCC voltada à etapa do ensino médio, acompanhada pela criação de um programa de incentivo à sua implementação, o ProBNCC, instituído pela Portaria no. 331, de 05 de abril [3].

Nesse contexto de mudança de currículo escolar cria-se a expectativa em torno das possíveis novidades e melhorias que isso possa proporcionar à educação brasileira. Entretanto, a reforma do ensino médio no âmbito da BNCC, compõe um velho discurso apresentado como algo novo, tendo como exemplo a centralidade em torno de um ensino por competências, retomando uma fala comum aos documentos e políticas curriculares do final da década de 1990 [4].

Nessa linha de raciocínio, um currículo pautado por competências, será incapaz de prover acesso ao conhecimento, sobretudo aquele inerente às diferentes disciplinas curriculares, vistas como constituintes de conjuntos de conceitos, sendo estes, por sua vez, os principais responsáveis pelo desenvolvimento intelectual dos estudantes [5, 6].

Considerando a importância de um ensino centrado em conceitos, vale destacar que a noção de geotecnologias presente na BNCC [7], corresponde muito mais a um meio do que a um fim, ou seja, representa uma estratégia para atingir um objetivo maior. Nesse caso, fica clara a necessidade dos estudantes dominarem a linguagem das geotecnologias para o desenvolvimento do pensamento espacial e para a resolução de problemas que envolvem informações geográficas, sendo algo muito específico da disciplina de Geografia, por mais que exista a possibilidade de interconexões com outras disciplinas escolares e áreas do conhecimento.

As geotecnologias também podem ser consideradas uma ferramenta para alcançar determinadas metas, tais como o desenvolvimento de pesquisas, as ações de planejamento e os processos de gestão e manejo que envolvem a estrutura do espaço geográfico. Neste caso, as geotecnologias são entendidas como as novas tecnologias inerentes ao campo das geociências e outras ciências correlatas [8].

Atualmente, as geotecnologias possuem uma aplicação que vai muito além da sala de aula na educação básica. As tecnologias de informação geográfica, ou seja, as geotecnologias, possuem funções e aplicações cada vez mais amplas e crescendo em quantidade, diversidade e complexidade, com destaque para os Sistemas de Informações Geográficas (SIG) como "[...] ferramentas centrais para a gestão do território e de todas as atividades como uma componente espacial" [9].

Além disso, vale ressaltar que nos últimos anos, as geotecnologias estão cada vez mais acessíveis às pessoas [10], dando a possibilidade para que os internautas construam seus próprios mapas (individual ou coletivamente) de maneira contínua, misturando diferentes linguagens e incorporando relações subjetivas das pessoas com os lugares, no que pode ser chamado de "prática cartográfica da cultura digital". Em complemento, vale lembrar que a informática democratizou a cartografia, tornando-a cada vez mais interativa, fato que reforça a importância da escola e, especialmente da Geografia escolar, na consolidação do conhecimento sobre cartografia durante a educação básica, de maneira a conduzir os estudantes a dominarem esse tipo de linguagem para que possam ter a autonomia suficiente para ler, interpretar e até mesmo produzir suas próprias representações cartográficas mediante 0 uso das geotecnologias [11].

Diante dessa contextualização apresentada anteriormente que envolve as incertezas da mudança de um currículo escolar, somado aos obstáculos atuais do ensino de aspectos relacionados às geotecnologias na educação geográfica da formação 
educacional básica, surgiu a possibilidade dos estudantes do ensino médio de uma rede de ensino filantrópica com unidades em São Paulo-SP e Jundiaí-SP, cursarem uma disciplina eletiva sobre geotecnologias aplicadas à dinâmica espacial das transformações do espaço urbano. Sendo assim, o objetivo principal desse artigo consiste em apresentar, de maneira crítica e contextualizada, um breve relato dos principais desafios e oportunidades que surgiram com o desenvolvimento dessa disciplina eletiva em âmbito escolar.

\section{Material e Métodos}

\subsection{Contextualização}

A disciplina eletiva em questão foi intitulada de Geotecnologias Aplicadas e foi ofertada aos educandos da $1^{\underline{a}}$ e $2^{\underline{a}}$ séries do ensino médio da rede de ensino conhecida como Colégios Vicentinos, com três colégios particulares no município de São Paulo (J.R. Passalacqua, São Vicente de Paulo - Penha e Santo Antonio de Lisboa) e outras duas unidades em Jundiaí (São Vicente de Paulo e Francisco Telles), município localizado a cerca de $60 \mathrm{~km}$ da capital paulista.

Considerando que uma das escolas de Jundiaí (Francisco Telles) não possui ensino médio e em uma das unidades educacionais de São Paulo (São Vicente de Paulo Penha) não houve compatibilidade de horários, a disciplina ocorreu, de fato, em três das cinco escolas da rede de ensino, totalizando um público-alvo de 28 estudantes, sendo sete do J.R. Passalacqua, nove do Santo Antonio de Lisboa e 12 do São Vicente de Paulo, em Jundiaí.

$\mathrm{Na}$ condição de disciplina eletiva, ficou à cargo dos alunos, caso tivessem interesse, de se inscreverem para participar das aulas que ocorreram no contraturno, ou seja, no período da tarde, com encontros que variaram em média a cada 15 dias, com duração de duas aulas de 50 minutos cada, ao longo do segundo semestre de 2019.

Vale lembrar que a BNCC, por meio da lei federal $n$ ‥ 13.415, de 16 de fevereiro de 2017 [12], dá a possibilidade das redes e instituições de ensino, de acordo com a relevância para o contexto local, organizar e oferecer diferentes arranjos curriculares, considerando o currículo básico do ensino médio e os itinerários formativos, divididos em cinco áreas do conhecimento (Linguagens e suas tecnologias, Matemática e suas tecnologias, Ciências da natureza e suas tecnologias, Ciências humanas e sociais aplicadas e Formação técnica e profissional).

$\mathrm{Na}$ prática, não existe uma clareza na BNCC em relação ao oferecimento dessas disciplinas eletivas, ficando a cargo da unidade escolar, conforme seus interesses e de seu público-alvo, se organizarem para viabilizar essas aulas. Entre 2018 e 2020, muitas escolas utilizaram essa flexibilidade curricular para o desenvolvimento de projetos-piloto como uma estratégia preparatória para seus catálogos de itinerários formativos, a serem implantados a partir de 2021. Por exemplo, em um desses projetos escolares, são apresentados os resultados de disciplina eletiva desenvolvida em uma escola estadual no município de São Carlos-SP, integrando as áreas de Ciências humanas e sociais aplicadas com a de Linguagens e suas tecnologias, com o objetivo de conduzir os estudantes do ensino fundamental a ampliarem sua interação com a música, oportunizando, dessa forma, estímulos e incentivos à criatividade [13].

Em outro exemplo, são relatados os principais desafios e resultados do desenvolvimento de uma disciplina eletiva, no primeiro semestre de 2018 , sobre matemática financeira em escola da rede estadual de ensino do município de Campos Belos-GO, que integrou disciplinas como Matemática, História e Sociologia e teve 
como um dos principais objetivos fomentar a cultura da educação financeira na formação escolar e cidadã [14].

Entre erros e acertos, as instituições e redes de ensino do país se organizaram para testar e analisar suas possibilidades em termos de itinerários formativos a serem oferecidos a partir do momento em que a BNCC se tornasse obrigatória. Nesse contexto, as disciplinas eletivas representam uma estratégia interessante para avaliar, por exemplo, o nível de aceitação por parte dos estudantes em relação à determinadas temáticas desenvolvidas ou às metodologias de ensino adotadas nessas aulas.

O oferecimento de disciplina eletiva ou aulas específicas no campo das geotecnologias possui como um dos maiores desafios a existência e a disponibilização de uma infraestrutura adequada, de maneira que os estudantes possam ter acesso à computadores ou notebooks e seus respectivos programas de geoprocessamento. Nesse sentido, não é comum encontrar cursos dessa natureza, sobretudo direcionados para os alunos do ensino médio.

De certa forma, isso mostra um pouco da dimensão dos desafios iniciais que recaíram sobre a estruturação e oferecimento de uma disciplina eletiva centrada em geotecnologias, incluindo um público-alvo diversificado de três colégios diferentes, localizados em dois municípios paulistas. Ou seja, havia a questão da infraestrutura, da tecnologia, do conteúdo em si e da logística de deslocamento entre os colégios.

\subsection{Expectativas}

Mesmo diante de todos os obstáculos anteriormente descritos, a disciplina eletiva foi apresentada aos estudantes no final do primeiro semestre de 2019 e ofertada entre os meses de agosto e dezembro do mesmo ano, buscando alcançar os seguintes objetivos específicos: (a) apresentar as possibilidades e oportunidades no campo das geotecnologias; (b) utilizar as geotecnologias como ferramenta de estudo interdisciplinar das relações entre sociedade e ambiente; (c) refletir sobre questões socioeconômicas e ambientais atuais em diferentes escalas temporais e espaciais; (d) dominar a linguagem de leitura, interpretação e produção de representações cartográficas.

\subsection{Desenvolvimento}

A viabilização da disciplina eletiva foi mediante a elaboração de uma sequência didática de aprendizagem estruturada em oito encontros presenciais, totalizando 16 aulas em cada um dos três colégios diretamente envolvidos.

Por sequência didática entende-se como um planejamento de atividades diversificadas de cunho pedagógico, com o objetivo de levar os educandos a refletir sobre um ou mais temas inerentes a uma disciplina escolar. Vale ressaltar que vários estudos foram desenvolvidos no Brasil nos últimos anos envolvendo sequências didáticas, em diferentes disciplinas e segmentos escolares [15]. Por exemplo, em um desses estudos foi utilizada a sequência didática no ensino de Geografia, levando os alunos do ensino médio de instituições estaduais de Minas Gerais, a refletir e registrar textualmente sobre fatos geográficos relevantes no contexto nacional e internacional, representados em charges [16].

Em termos de conteúdos trabalhados durante as aulas da eletiva de Geotecnologias, foi estruturada uma ementa que contemplou aspectos introdutórios da evolução, desafios e oportunidades das geotecnologias no Brasil e no mundo, associado à 
utilização de softwares de geoprocessamento, tais como o QGIS e o Google Earth Pro. Também foi desenvolvido junto aos estudantes as habilidades de elaboração de representações cartográficas e a investigação científica de problemas urbanos reais e atuais. Na Figura 1, a seguir, pode-se observar uma das aulas em que os discentes tiveram a oportunidade de praticar a técnica de elaboração de mapas utilizando o software QGIS.

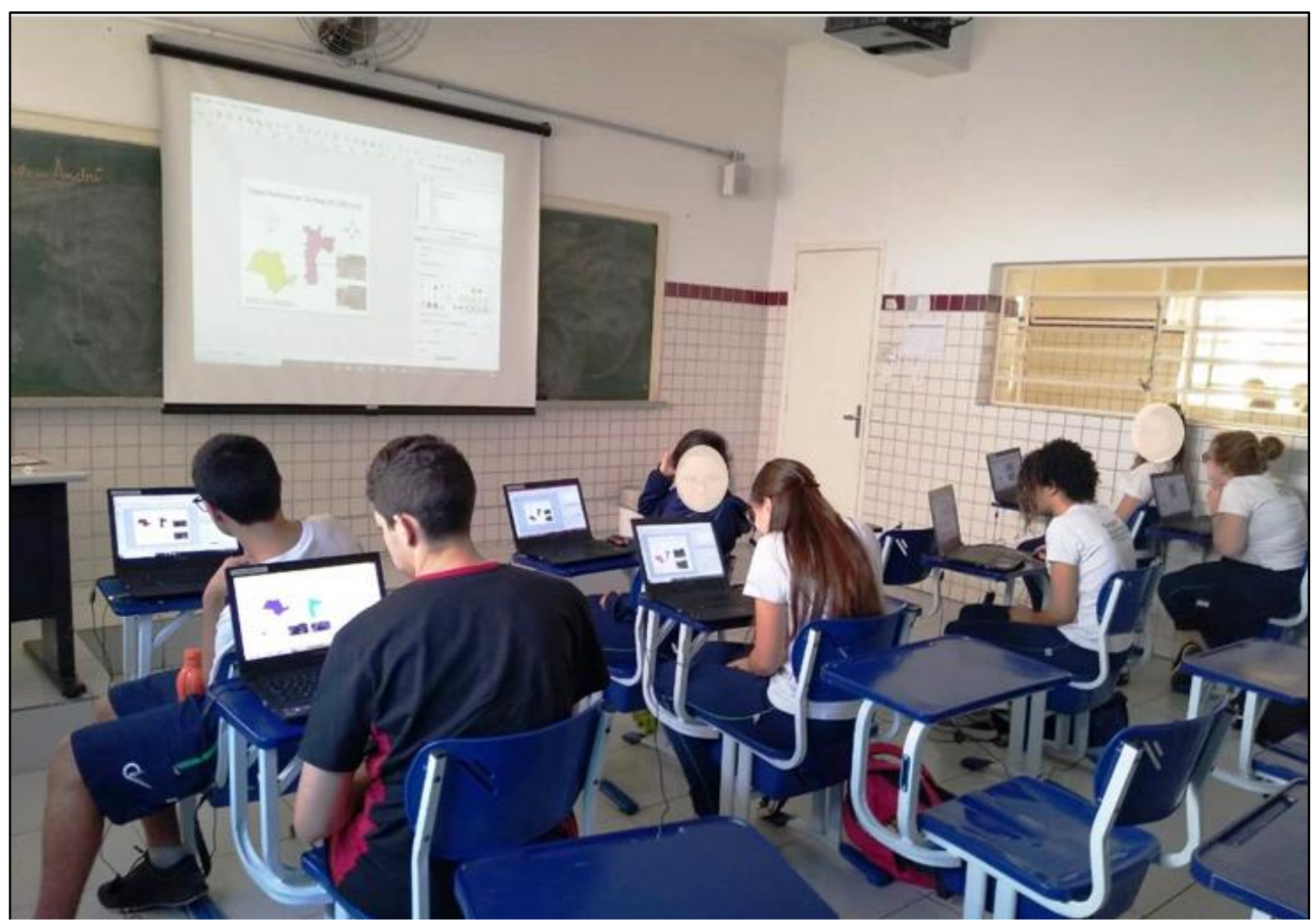

Figura 1. Estudantes do colégio J.R. Passalacqua em uma das aulas da disciplina eletiva de Geotecnologias. Fonte: Conceição (2019).

Além da abordagem do conteúdo, ao longo das 16 aulas também foram destinados alguns encontros para que os alunos fizessem as avaliações da disciplina, tal como a apresentação de um trabalho em grupo para uma banca de professores e à resposta de uma autoavaliação.

\section{Resultados e Discussão}

Os resultados aqui apresentados podem ser agrupados em três categorias, tais como as representações cartográficas criadas pelos estudantes, individual ou coletivamente, durante as aulas; a das apresentações de projeto por meio de seminários; e a autoavaliação que os educandos fizeram em relação ao desempenho individual e o aprendizado que tiveram na disciplina eletiva.

\subsection{Representações cartográficas}

Um dos propósitos e, ao mesmo tempo, diferenciais da disciplina eletiva de Geotecnologias Aplicadas foi a dinâmica de realização de aulas predominantemente práticas, onde os alunos, desde o primeiro encontro, tiveram a oportunidade de interagir com os softwares de geoprocessamento e elaborar suas próprias 
representações cartográficas. A Figura 2, a seguir, mostra uma das produções feitas pelos discentes durante as aulas.

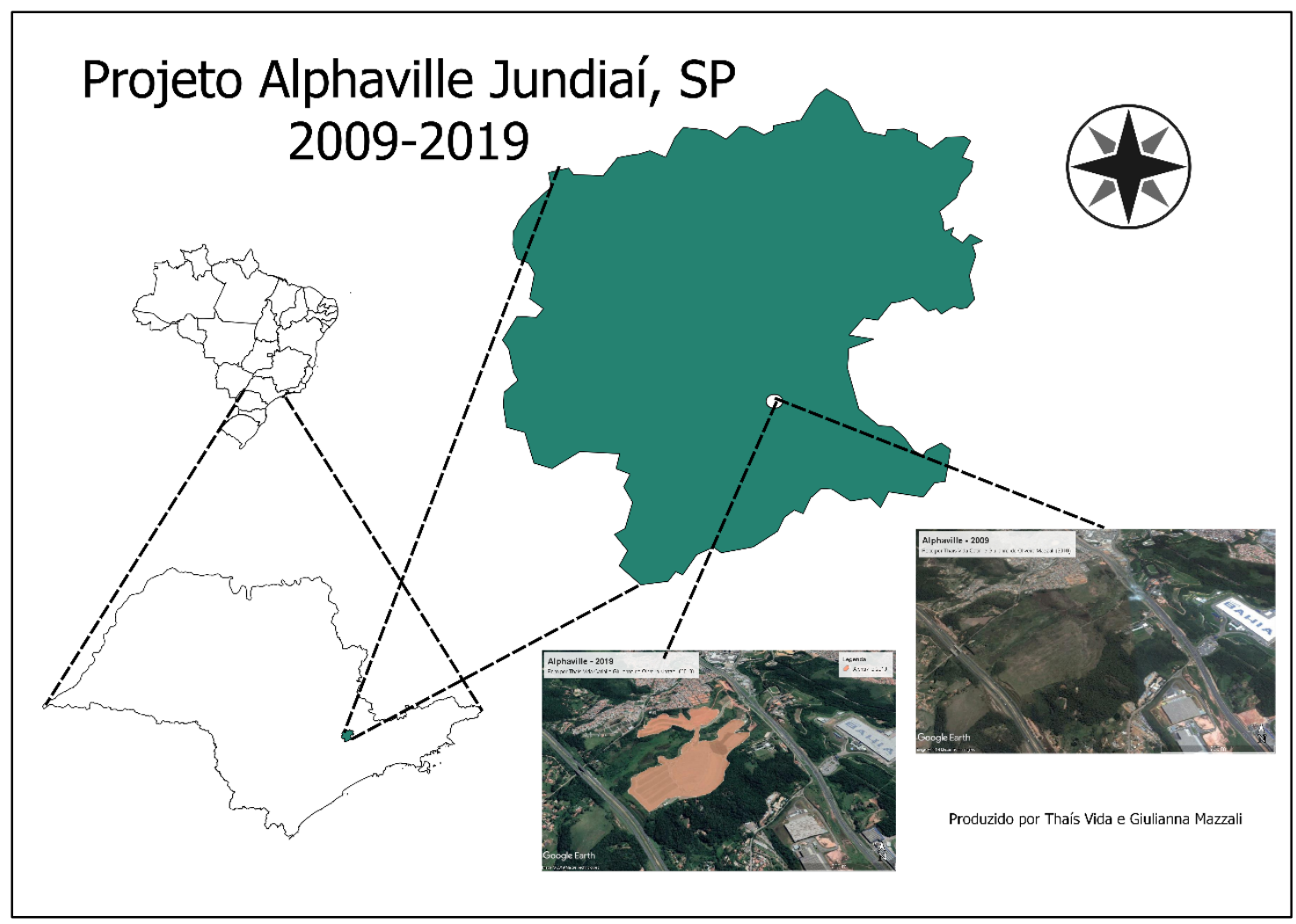

Figura 2. Exemplo de produção cartográfica feita por alunas do colégio São Vicente de Paulo, em Jundiaí-SP. Fonte: Vida; Mazzali (2019).

Essa produção (Figura 2), que inclui uma composição com mapas e imagens de satélite, foi o resultado de um projeto que os estudantes tiveram que desenvolver a partir da segunda metade do período de oferecimento da disciplina e teve como objetivo mapear e analisar as transformações espaciais e temporais em determinadas localidades do espaço urbano dos municípios onde os colégios estão situados.

Para os estudantes do colégio de Jundiaí, o desafio foi analisar a construção de um condomínio residencial de alto padrão em um dos eixos atuais de crescimento urbano do município. No caso do colégio J.R. Passalacqua, os alunos foram desafiados a analisar as mudanças ocorridas com a construção de um loteamento residencial no distrito de Parelheiros, localizado na zona Sul do município de São Paulo (Figura 3). Por fim, os discentes do colégio Santo Antonio de Lisboa analisaram as transformações socioeconômicas e ambientais promovidas no bairro de Artur Alvim, na zona Leste da capital paulista, após a construção da Neo Química Arena (Figura 4).

O elemento comum aos três projetos escolares foi o estudo da cidade, entendido como metodologia do ensino de Geografia capaz de desenvolver no estudante, entre outros aspectos, a formação de uma cidadania consciente, participativa e democrática, tendo como referência básica a realidade mais imediata dos alunos, o que justifica a escolha de localidades e regiões de estudo nos respectivos municípios dos colégios [17]. 
Em complemento, o desenvolvimento desses projetos escolares possibilitou aos estudantes ampliar seu domínio da linguagem cartográfica por meio da metodologia do "aluno mapeador", em que a vivência das funções cartográficas possibilita a aprendizagem de conceitos e noções para entender o que são objetos presentes no espaço, levando ao desenvolvimento das habilidades e o conhecimento em potencial de ler e entender o mundo [18].

\section{Projeto Parelheiros em São Paulo - SP (2009 - 2019)}

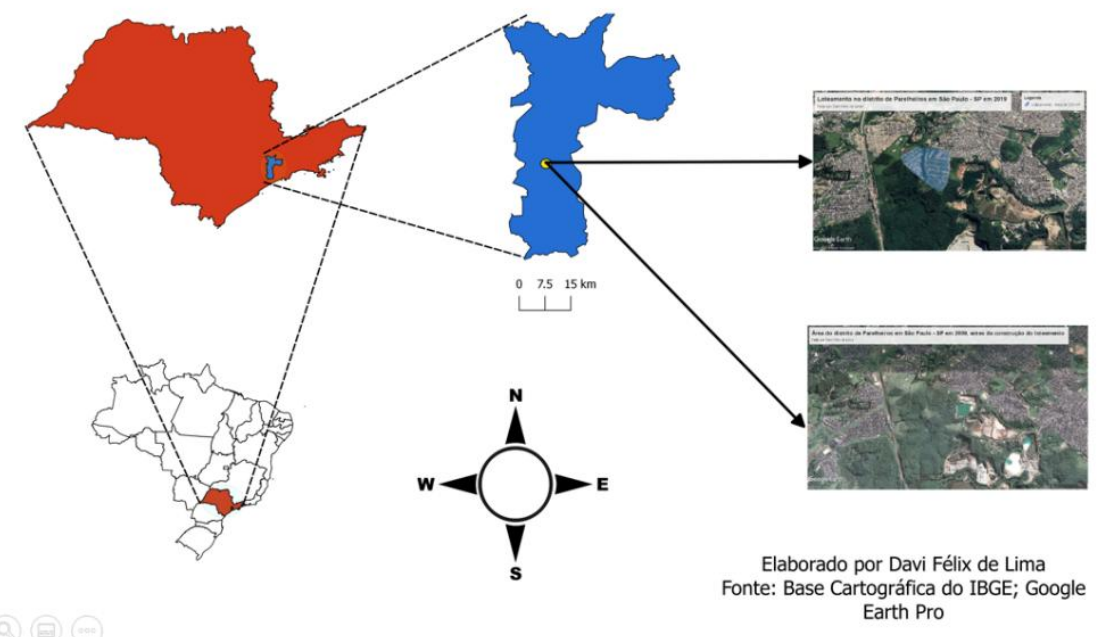

Figura 3. Exemplo de produção cartográfica feita por aluno do colégio J.R. Passalacqua, em São Paulo-SP. Fonte: Lima (2019).

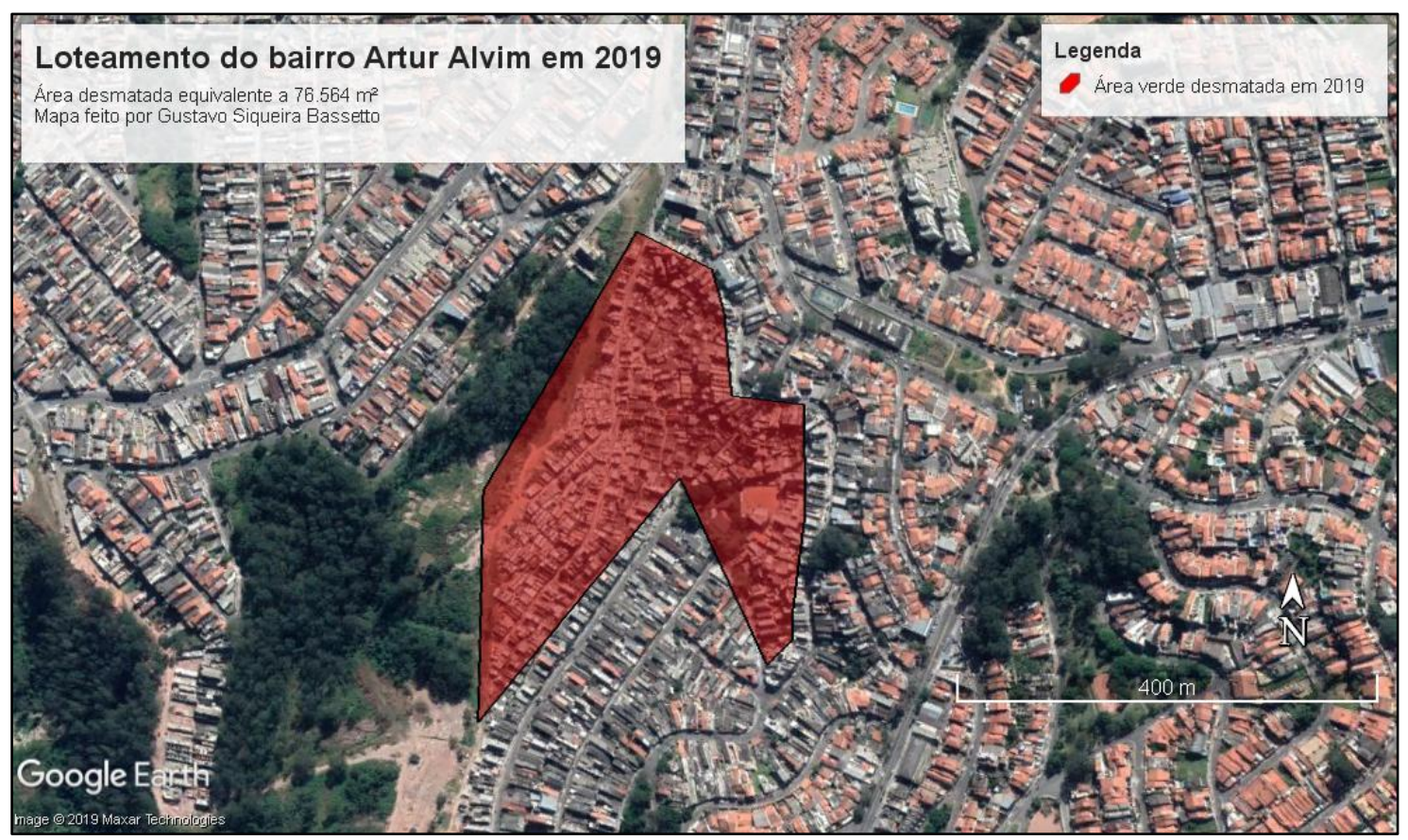

Figura 4. Exemplo de produção cartográfica feita por aluno do colégio Santo Antonio de Lisboa, em São Paulo-SP. Fonte: Bassetto (2019). 


\subsection{Seminários}

Nesse momento da disciplina eletiva, os estudantes, organizados em grupos de dois à três integrantes cada, tiveram o espaço necessário para apresentar seus projetos e respectivas produções cartográficas sobre a localidade e região urbana de estudo. Para avaliar os trabalhos, foi formada uma banca composta por ao menos dois docentes dos próprios colégios. Na Figura 5, a seguir, consta o momento de uma dessas apresentações.

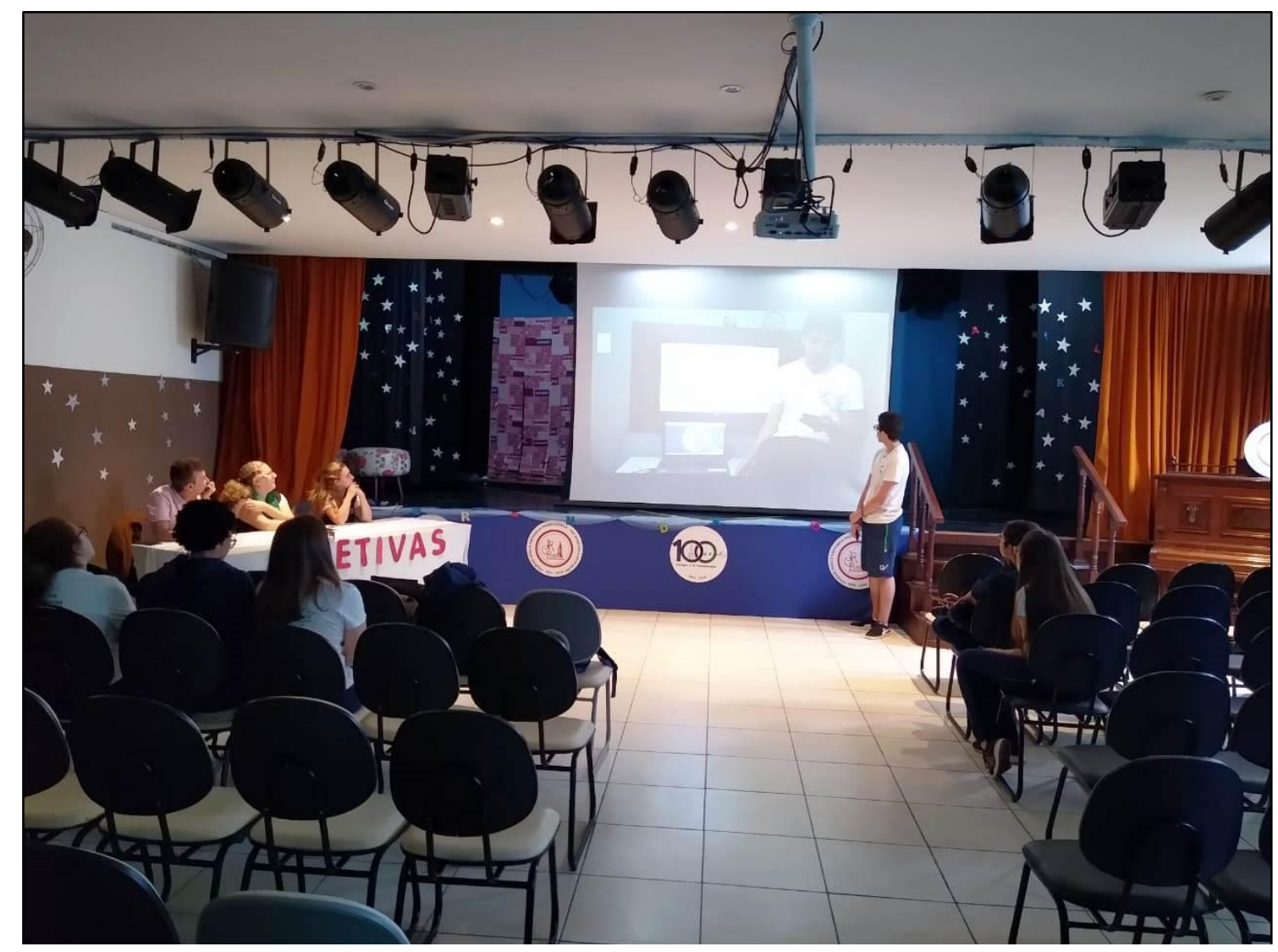

Figura 5. Apresentação do projeto final da disciplina eletiva de Geotecnologias Aplicadas no colégio J.R. Passalacqua, em São Paulo-SP.

Para otimizar os seminários e não deixá-los repetitivos, foi feita uma organização de maneira que cada grupo analisasse e expusesse apenas parte do projeto escolar desenvolvido. Por exemplo, o primeiro grupo abordou sobre a metodologia de elaboração das representações cartográficas, já o segundo grupo focou nas características da localização e perfil socioeconômico da área de estudo, enquanto o terceiro grupo, compartilhou sobre as principais transformações e impactos socioeconômicos e ambientais na área estudada. Dessa forma, criou-se um ambiente bastante propício para as trocas de informações entre os envolvidos sobre questões importantes e complexas da sociedade contemporânea.

No ensino de Geografia, tratar de questões complexas no mundo contemporâneo requer procedimentos metodológicos que possam levar os estudantes a compreender melhor o contexto em que está inserido, desenvolvendo determinados conteúdos procedimentais, tais como a busca por explicações, a realização de pesquisas e a articulação de argumentações [19]. 


\subsection{Autoavaliação}

Essa foi a oportunidade que os educandos tiveram para refletir sobre o aprendizado e o nível de satisfação obtido na disciplina eletiva. Nesse sentido, foi solicitado aos alunos que atribuíssem uma menção para o desempenho individual no desenvolvimento das atividades relacionadas à disciplina de Geotecnologias Aplicadas. A Figura 6, a seguir, expõe os resultados obtidos a partir do ponto de vista dos discentes que responderam ao questionamento.

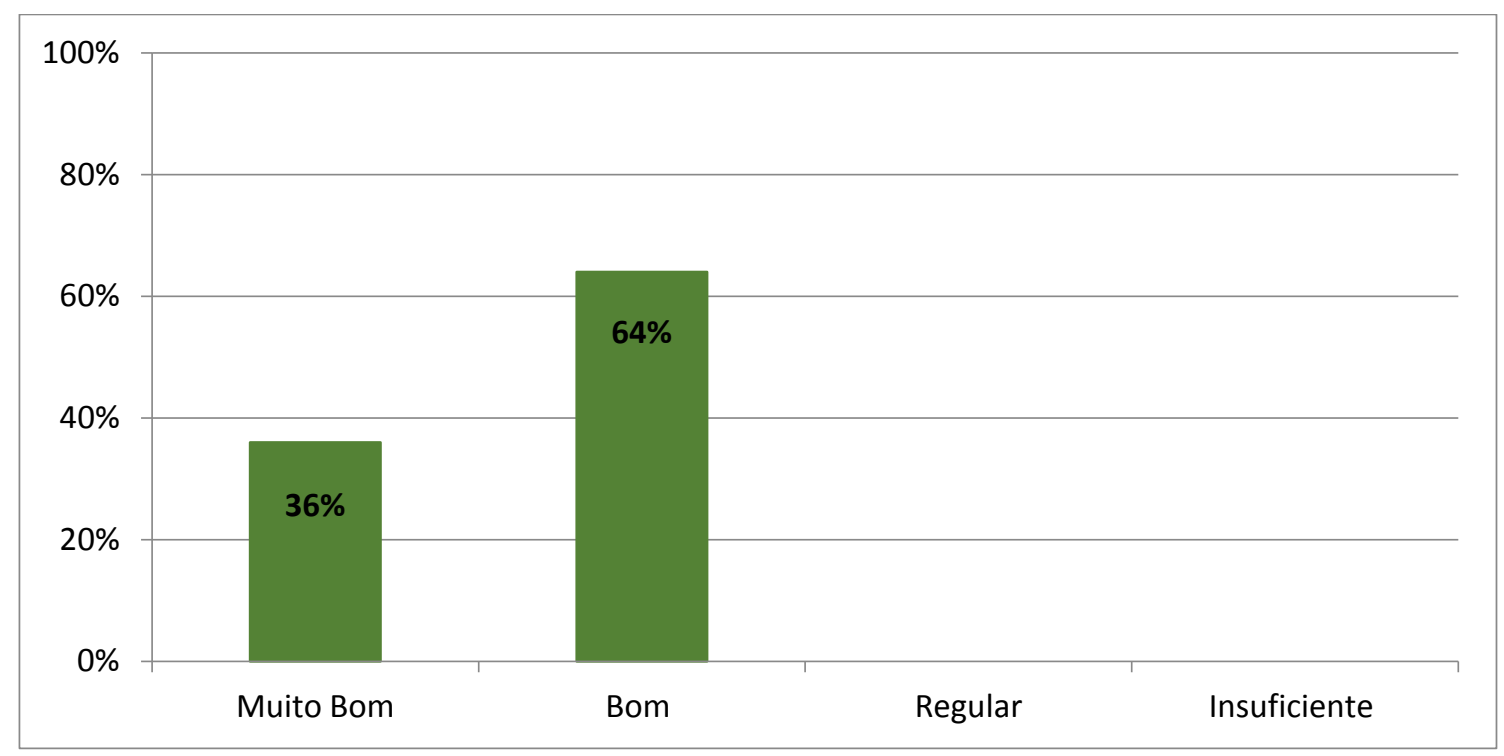

Figura 6. Menções dadas pelos próprios estudantes ao desempenho individual no desenvolvimento da disciplina eletiva.

É notável que os alunos tiveram uma percepção de avaliação bastante satisfatória em relação ao desempenho individual durante o período de oferecimento da disciplina eletiva de Geotecnologias Aplicadas. Reforça esse dado o relato apresentado na sequência:

"Por mais que eu tenha dificuldade ao lidar com computadores, fiz um grande esforço para obter o máximo possível de aprendizado e realizar todas as atividades." (Estudante G. V. G. do colégio São Vicente de Paulo, 2019).

Conforme pontuado anteriormente, a dificuldade com a tecnologia foi uma das colocações mais recorrentes feitas pelos alunos para justificar um rendimento não tão bom ou satisfatório como se poderia imaginar. Sendo assim, a disciplina eletiva também contribuiu, direta e indiretamente para a incorporação das Tecnologias de Informação e Comunicação - TIC aos processos de ensino e aprendizagem. $O$ público-alvo da educação básica, ou seja, as crianças e os adolescentes, estão cada vez mais conectados às tecnologias digitais, representando uma geração que estabelece novas relações com o conhecimento, fato que, de certa forma, pressiona a escola para que também se modifique diante dessas recentes transformações tecnológicas [20].

Outro aspecto que os estudantes tiveram a oportunidade de avaliar foram os conteúdos aprendidos na disciplina eletiva. A Figura 7, na sequência, sintetiza esses dados. 


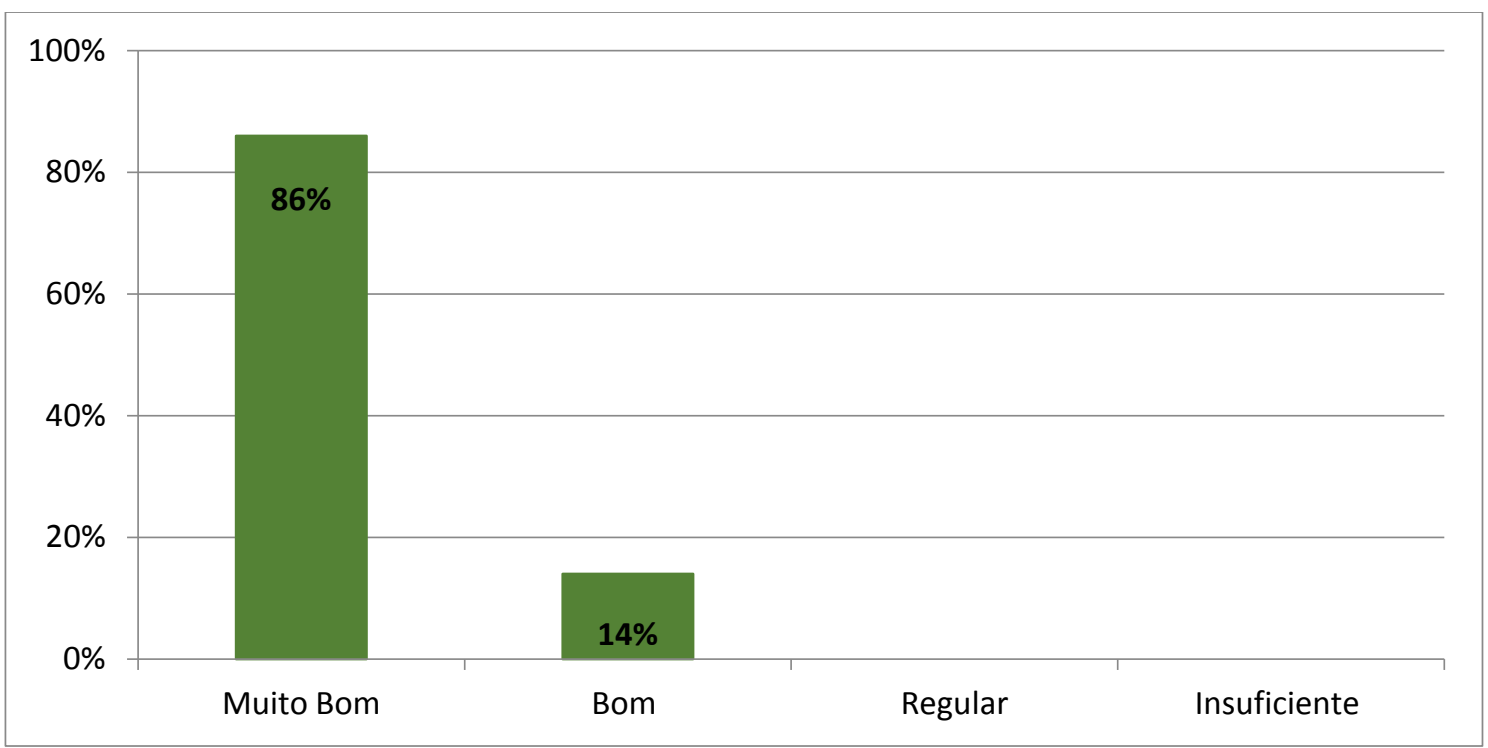

Figura 7. Menções atribuídas pelos estudantes aos conteúdos aprendidos na disciplina eletiva.

Em geral, percebe-se que a avaliação dos educandos em relação aos conteúdos aprendidos na eletiva foi extremamente positiva, visto o elevado percentual de menções classificadas como "Muito bom". Corrobora isso, o seguinte relato feito por uma cursista da disciplina:

"Com a eletiva aprendi conteúdos que eu jamais pensei que um dia fosse aprender. Saber mexer direitinho nos aplicativos como o Google Earth Pro e o QGIS possibilitou que eu compreendesse o quão importante a Geotecnologia pode ser no nosso dia a dia, já que ela amplia nossa visão de mundo, sobre a realidade ao nosso redor." (Estudante A. J. O. M., do colégio J.R. Passalacqua, em São Paulo-SP).

Novamente a tecnologia, em especial a geotecnologia, é citada nesse e em outros relatos feitos pelos discentes como um novo e interessante aprendizado em seus processos de formação escolar. Nesse sentido, a evolução dos recursos tecnológicos aplicada ao contexto educacional pode proporcionar aos alunos uma formação mais abrangente, que aliada ao domínio e correta utilização pelos docentes dessas tecnologias, tende a contribuir para a construção conjunta e significativa do conhecimento. Além disso, nessa linha de pensamento, os estudantes podem enriquecer seus cotidianos e ficarem mais estimulados pela disciplina e seus respectivos conteúdos, contribuindo para a materialização de um processo mais amplo de transposição de currículos escolares tradicionais [21].

Em outro ponto da autoavaliação, foi perguntado aos estudantes sobre o maior aprendizado que obtiveram com o desenvolvimento das atividades propostas na disciplina. No relato destacado a seguir, consta uma importante reflexão feita por uma das estudantes:

"Eu diria que o maior [aprendizado] antecede a questão dos softwares e da tecnologia, mas foi aprender a olhar para as situações com um olhar crítico e entender que a tecnologia de nada vale se não for para gerar conforto e vida ao ser humano 
ao invés de tirar os direitos básicos deste”. (E. A., estudante do colégio J.R. Passalacqua, em São Paulo-SP).

Na perspectiva da aluna é possível notar sua compreensão das geotecnologias como um conjunto de ferramentas que permite ampliar sua visão de mundo. Dessa forma, atinge-se uma das principais contribuições que o ensino de Geografia pode proporcionar no contexto da educação básica, ou seja, o de levar o aluno a compreender o lugar em que vive e nele atuar, preferencialmente numa abordagem crítico-reflexiva da sociedade [22].

\section{Conclusão}

A realização da disciplina eletiva de Geotecnologias Aplicadas foi bastante satisfatória como uma prática de ensino de Geografia, sendo muito bem avaliada quali e quantitativamente pelos estudantes. Além disso, conseguiu contemplar todas as expectativas inicialmente traçadas, visto que apresentou aos alunos da educação básica, algumas possibilidades de aplicações fazendo uso de geotecnologias, sobretudo na análise espaço-temporal de questões complexas que envolvem as relações socioeconômicas e ambientais entre sociedade e ambiente em contexto urbano. Por fim, a eletiva também auxiliou na consolidação do domínio da capacidade dos alunos de leitura, interpretação e produção de representações cartográficas, fato que aproxima esses educandos das TICs.

Vale destacar que a maior dificuldade encontrada para o desenvolvimento da disciplina foi a logística de deslocamento entre três colégios situados em municípios diferentes. Isso impôs o trânsito constante dos notebooks utilizados durante as aulas. Salas fixas de informática em cada colégio com boa oferta de notebooks e/ou computadores bem equipados reduziria esse obstáculo. Entretanto, é necessário destacar que esse pequeno problema não interferiu na dinâmica das aulas ou nos conteúdos trabalhados.

Como sugestão para futuros projetos escolares que possam ter o presente trabalho como referência, fica a recomendação, caso seja possível e de acordo com a realidade local, de ampliar o número de aulas e torná-las menos espaçadas no calendário escolar, pois ficou nítido que, em situações de encontros quinzenais, os estudantes demoravam mais para retomar os conteúdos da aula anterior o que reduzia o tempo dedicado para interagir com os softwares de geoprocessamento e a elaboração das representações cartográficas.

De qualquer forma, apesar de algumas poucas dificuldades encontradas, é inegável que os resultados foram positivos, representando um exemplo de metodologia da educação geográfica em contexto do ensino básico, capaz de levar a um processo de aprendizagem significativo, criativo, crítico, contextualizado e alinhado com as principais diretrizes curriculares nacionais.

\section{Referências}

[1] Brasil - Ministério da Educação. Portaria no 592, de 17 de janeiro de 2015. Institui a Comissão de Especialistas para a Elaboração de Proposta da Base Nacional Comum Curricular [documento da internet]. Brasília; 2015 [acesso em 28 dez 2020]. Disponível em: <http://portal.mec.gov.br/docman/setembro-2015-pdf/21361-port-592-bnc-21-set2015-pdf>. Acesso em: 09 de mar. 2021.

[2] Brasil - Ministério da Educação. Portaria no 1.570, de 20 de dezembro de 2017 [documento da internet]. Brasília, 2017 [acesso em 28 dez 2020]. Disponível em: 
<http://basenacionalcomum.mec.gov.br/images/historico/PORTARIA1570DE22DEDEZ EMBRODE2017.pdf>. Acesso em: 09 de mar. 2021.

[3] Brasil - Ministério da Educação. Portaria no 331, de 05 de abril de 2018. Institui o programa de Apoio à Implementação da Base Nacional Comum Curricular - ProBNCC e estabelece diretrizes, parâmetros e critérios para sua implementação [documento da internet]. Brasília, 2018 [acesso em 28 dez 2020]. Disponível em: <http://basenacionalcomum.mec.gov.br/images/historico/PORTARIA331DE5DEABRIL DE2018.pdf>. Acesso em: 09 de mar. 2021.

[4] Silva M.R. A BNCC da reforma do Ensino Médio: o resgate de um empoeirado discurso. Educação em Revista 2018; 34: e214130. http://dx.doi.org/10.1590/01024698214130.

[5] Young M.F.D. O futuro da educação em uma sociedade do conhecimento: o argumento radical em defesa de um currículo centrado em disciplinas. Revista Brasileira de Educação 2011; 16(48): 609-623. https://doi.org/10.1590/S141324782011000300005.

[6] Young M.F.D. Teoria do currículo: o que é e por que é importante. Cadernos de Pesquisa 2014; 44(151): 190-202. https://doi.org/10.1590/198053142851.

[7] Brasil - Ministério da Educação. Base Nacional Comum Curricular: Educação é a Base. Brasília: $\quad$ MEC; $2018 . \quad 600 \quad$ p. $<$ http://basenacionalcomum.mec.gov.br/images/BNCC_EI_EF_110518_versaofinal_sit e.pdf>. Acesso em: 09 de mar. 2021.

[8] Fitz P.R. Geoprocessamento sem complicação. São Paulo: Oficina de Textos; 2008. 160 p.

[9] Cosme A. Projetos em Sistemas de Informação Geográfica. Lisboa: Lidel; 2012. $366 \mathrm{p}$.

[10] Canto T.S., Almeida R.D. Mapas feitos por não cartógrafos e a prática cartográfica no ciberespaço. In.: Almeida, R. D. (org.). Novos rumos da cartografia escolar. São Paulo: Contexto; 2019, 147-162 p.

[11] Ramos C.S. Visualização cartográfica e cartografia multimídia: conceitos e tecnologias. São Paulo: Editora UNESP; 2005. 179 p.

[12] Brasil - Ministério da Educação. Lei no 13.415, de 16 de fevereiro de 2017 [documento da internet]. Brasília, 2017. [acesso em 29 dez 2020]. Disponível em: <http://www.planalto.gov.br/ccivil_03/_ato2015-2018/2017/lei/l13415.htm>. Acesso em: 09 de mar. 2021.

[13] Araújo A.R.I., Lourenço D.M.S., Franchini G.E., Rossales L. Música na escola: um relato de experiência. Cadernos da Pedagogia 2020; 28(14). <http://www.cadernosdapedagogia.ufscar.br/index.php/cp/article/view/1389/531>.

Acesso em 09/03/2021.

[14] Silva G.F., Souza K.C.O., Costa E.A. A matemática financeira para além da escola. Colloquium Humanarum 2020; 17(1): 155-166. https://doi.org/10.5747/ch.2020.v17.h465. 
[15] Mesquita E.M., Leão C.M.E., Souza D.F.B.G. As sequências didáticas como um procedimento de ensino para o gênero artigo de opinião. Revista de Letras 2016; 18(22): 55-74. <https://revistas.utfpr.edu.br/rl/article/download/2911/3157>. Acesso em 09/03/2021.

[16] Mendes F.F. Ensino de geografia: limites e possibilidades na utilização de charges. Revista Eletrônica Geoaraguaia 2012; 2(1): 86-100. <http://periodicoscientificos.ufmt.br/ojs/index.php/geo/article/view/4808/3218>. Acesso em: 29 de dez. 2020.

[17] Cavalcanti L.S. Ensino de Geografia e diversidade: construção de conhecimentos geográficos escolares e atribuição de significados pelos diversos sujeitos do processo de ensino. In.: Castellar S. (org.). Educação geográfica: teorias e práticas docentes. São Paulo: Contexto; 2017. p. 66-78.

[18] Passini E.Y. Alfabetização cartográfica e a aprendizagem de geografia. São Paulo: Cortez; 2012. 215 p.

[19] Pontuschka N.N., Paganelli T.I., Cacete N.H. Para ensinar e aprender Geografia. São Paulo: Cortez; 2009. 383 p.

[20] Bacich L., Tanzi Neto A., Trevisani F.M. Ensino Híbrido: personalização e tecnologia na educação. Porto Alegre: Penso; 2015. 270 p.

[21] Santos M.F.P., Pinto M.V.M., Galdino V.H. O Facebook no ensino de Geografia: desafios e possibilidades. In.: Sacramento A.C.R., Antunes C.F., Santana Filho M.M. (orgs.). Ensino de Geografia: produção do espaço e processos formativos. Consequência: Rio de Janeiro; 2015. 392 p.

[22] Silva A.C.P., Rodrigues R.C.A., Andrade M.A.A., Villela T. Espaço e cidadania: uma importante relação dos lugares com o saber. In.: Silva A.C.P., Rodrigues R.C.A., Andrade M.A.A., Villela T. Educação geográfica em foco: temas e metodologias para o ensino básico. Rio de Janeiro: Lamparina; 2014.

\section{Agradecimentos}

Pela oportunidade de oferecimento e desenvolvimento dessa disciplina escolar, fica o agradecimento especial à Direção, à Orientação Pedagógica e Educacional dos Colégios Vicentinos, bem como a equipe de informática das unidades escolares quanto à assistência técnica em relação aos notebooks e softwares de geoprocessamento.

\section{Autores}

André Luiz da Conceição

Departamento de Geografia e Planejamento Ambiental, Universidade Estadual Paulista - UNESP Júlio de Mesquita Filho, Avenida 24-A, 1515, Rio Claro - SP, Brasil.

\footnotetext{
*Autor para correspondência: andre.I.conceicao@unesp.br
} 